\title{
A Systematic Analysis and Synthesis of Case Study Based Agile Scaling Research in the Context of Digital Transformations
}

\author{
Everist Limaj and Edward W.N. Bernroider \\ Vienna University of Economics and Business (WU), Institute for Information Management and Control, Vienna, Austria \\ \{everist.limaj, edward.bernroider\}@wu.ac.at
}

\begin{abstract}
Over the past decade, agile scaling concepts in organizations have gained considerable momentum and renewed attention especially from business practice. While agility has its roots in software development, the concept of agile at scale aims at more generally applying agile practices in organizations across different industries. Academic research is serving this development in different disciplines, most notably the management and information systems fields. This short paper takes stock of the last 12 years of scholarly research by developing a systematic content analysis of 26 case studies dealing with agile scaling concepts in the context of digital transformation. In the attempt to narrow the gap between research and practice, we focus on case studies as a strategic research methodology providing rich insights of complex real-life processes such as agile scaling. The findings synthesize the current state of knowledge in this regard and offer new research avenues contributing to the present agile scaling discourse.
\end{abstract}

Keywords: Systematic Literature Review, Agile Scaling, Digital Transformation

\section{Introduction}

Since the publication of the Agile manifesto [1], many so-called agile transformations of organizations have been implemented worldwide [2]. Most commonly, these change initiatives are driven by the need of organizations to keep up with the trends of the digitalization era (i.e. in-depth understanding of customer requirements, rapid creation of novel digital services, ongoing process renewal, and updates of business models) [3]. Usually utilized in software development teams, agile at scale is being adopted in other industries at different management and operational levels shaping new organizational forms [4]. Agile at scale can be understood as a process of diffusing the initial adoption of agile principles and methods to more organizational structures [5]. The increasing application of agile concepts at the organizational level has also resulted in a growing amount of agile scaling case studies provided by scholarly research. Yet, to date, (as we highlight in the next section) research lacks a compelling (i.e. rigorous) assessment of this emergent literature.

This article seeks to fulfil this gap by conducting a thorough examination of the accumulated agile scaling body of research in relation to case studies, which provide "an in-depth exploration from multiple perspectives of the complexity and uniqueness of a particular project, policy, institution, program or system in real life" [6, p.21]. We purposefully chose to restrict our selection to case studies only, as we intend to develop practice-based scientific knowledge to narrow the gap between theory and practice in the agile domain [7]. Accordingly, based on guidance from Webster and Watson [8], we selected 26 case studies from the agile scaling literature and analyzed them by means of a conceptcentric review. The resulting concept matrix contributes to the agile scaling discourse in providing a synthesis of extant research and motivating new research avenues. The remainder of this article proceeds with an examination of previous literature reviews conducted in the agile scaling area. Next, we describe the methods used for data collection and analysis before presenting the result of our systematic literature review. The article concludes by discussing insights for promising directions of future research. 


\section{Past literature reviews on agile transformation}

For our examination of prior research conducting literature reviews in relation to agile scaling, we identified 9 peerreviewed publications listed in Table 1, which shows their publication years, review scopes and types of review. Notably, only three industry specific reviews are included (one related to healthcare, two to software industry), while six studies are comprehensive in scope reviewing agile literature across industries. Besides, only two articles actually use methodologically rigorous literature review guidelines (i.e. systematic reviews), while the others give scarce information on selection criteria and methods of analysis. The most commonly investigated topic is concerned with agile challenges [papers No. 2, 3, 6, 7, 9 in Table 1]. Other common topics include agile strategies [papers No. 1 and 4], agile capabilities [papers No. 1, 4, 5], agile success factors [papers No. 3 and 6], agile benefits [papers No. 7, 9], and agile research streams [paper No. 8].

Table 1. Summary of previous reviews on agile scaling

\begin{tabular}{|c|c|c|c|c|c|c|}
\hline Paper No. & Year & Author(s) [Reference] & \multicolumn{2}{|c|}{$\begin{array}{l}\text { Review scope } \\
\end{array}$} & \multicolumn{2}{|c|}{ Type of review } \\
\hline & & & Comprehensive & Industry specific & Systematic & Other \\
\hline 1 & 2015 & Tolf, Nyström [9] & & $x$ & & $x$ \\
\hline 2 & 2015 & Gregory, Barroca [10] & $x$ & & & $x$ \\
\hline 3 & 2016 & Dikert, Paasivaara [2] & & $x$ & $x$ & \\
\hline 4 & 2017 & Appelbaum, Calla [11] & $x$ & & & $x$ \\
\hline 5 & 2017 & Appelbaum, Calla [12] & $x$ & & & $x$ \\
\hline 6 & 2017 & Paterek [13] & $x$ & & & $x$ \\
\hline 7 & 2017 & Abdalhamid and Mishra [14] & & $x$ & $x$ & \\
\hline 8 & 2018 & Sońta-Drączkowska [15] & $x$ & & & $x$ \\
\hline 9 & 2018 & Putta, Paasivaara [16] & $x$ & & & $x$ \\
\hline & & Total number of articles & 6 & 3 & 2 & 7 \\
\hline
\end{tabular}

Most commonly identified agile challenges seem not new to organizational change research (e.g. resistance to change, difficulties to plan, changing the culture and lack of investments $[2,16])$. More recent issues include controversies with the agile framework, struggle to manage agile methodologies, and difficulties to measure agile value, coordinate multiple teams and integrate non-agile functions. Yet, with few exceptions [2, 10], previous reviews scarcely formulate emergent research topics associated to agile challenges in practice.

With regard to the topics of agile strategies and capabilities, Tolf and Nyström [9] highlight proactive, reactive and embracive strategies as well as five core capabilities (inter-organizational links, market sensitivity, self-organizing employees, elastic organic structures, and timely delivery) needed for healthcare organizations to cope with external uncertainty. Besides, Appelbaum et al., in two publications argue that organizational agile transitions require change at all levels (e.g. strategy, processes, and people) while hinting that there is little information on how to develop agile capabilities.

Considerable research has been devoted to point out agile success factors (e.g. management support, customized agile approach, piloting, training, agile coach, communication and transparency, mindset and alignment, team autonomy, culture of continuous learning, and community of practice $[2,13])$ and agile benefits (e.g. increase in quality, transparency, collaboration, productivity and alignment [16, 17]. However, one concern is that most of these success factors and benefits are identified from experience reports that have a tendency to emphasize positive views [2].

With regard to research streams, the review of Sońta-Drączkowska [15] proposes five themes, agile in software development, agile in project management, agile organization, hybrid approaches and agile in innovations. The authors recognize that agile concepts are dispersed in a wide range of domains, hence more studies are needed especially to link agile projects with the organizational level [15].

To summarize, while previous literature reviews have provided helpful insights (especially identifying agile challenges and success factors), there still seems to be gap in prior review work providing an overview on how scholars have covered scaling agile in case studies in relation to how scaling agile is defined, understood and applied. 


\section{Data collection}

Our data collection follows a rigorous process guided by previous research on conducting systematic literature reviews $[8,18,19]$. We focused article selection on case studies that provide information on agile scaling in a digital transformation context, and, thus address the cross section between management and IS research. To guarantee objectivity in the selection procedure, we developed a research protocol describing the search strategy including the databases used for the search, and inclusion and exclusion criteria (Table 2).

Table 2. Research protocol (Source: adapted from [15])

\begin{tabular}{|c|c|}
\hline Dimension & Description \\
\hline $\begin{array}{l}\text { Research data- } \\
\text { bases }\end{array}$ & $\begin{array}{c}\text { The databases used for the search process were based on recommendations by Levy and } \\
\text { Ellis (2006), and include ProQuest, Science Direct, IEEE, ACM, JSTOR, Wiley, Lea Jour- } \\
\text { nals, EBSCOhost and AIS library. }\end{array}$ \\
\hline Publication type & Only peer-reviewed full papers \\
\hline Language & Only papers published in English \\
\hline Methodology & Only case studies \\
\hline Date range & $\begin{array}{l}\text { As the research on this topic is relatively recent, the range of our examination was lim- } \\
\text { ited to the time frame of } 2007 \text { to } 2019 \text {. We consider this } 12 \text {-year period representative of } \\
\text { the adaptation of agile at scale. }\end{array}$ \\
\hline Search fields & Title, abstract and keywords section \\
\hline Search terms & $\begin{array}{c}\text { Boolean search combining terms: (“scaling agile” OR “agile at scale”) AND (“digital } \\
\text { transformation” OR “digitalization” OR "organizational transformation” OR “organiza- } \\
\text { tional change”) }\end{array}$ \\
\hline Inclusion criteria & $\begin{array}{l}\text { Only articles that consider agile as a management practice, or those positioned in an ag- } \\
\text { ile transformation context, or those that deal with organizational change by scaling agile. }\end{array}$ \\
\hline $\begin{array}{l}\text { Exclusion crite- } \\
\quad \text { ria }\end{array}$ & $\begin{array}{l}\text { Articles were removed considering agile only as a method for software development or } \\
\text { as an operational issue, and not at the organizational level (e.g. focusing only at a project } \\
\text { level or team level). }\end{array}$ \\
\hline $\begin{array}{l}\text { Data analysis } \\
\text { and synthesis }\end{array}$ & $\begin{array}{l}\text { We used techniques of grounded theory to code the data, identify patterns and map rela- } \\
\text { tionships. The qualitative software NVIVO supported this process. }\end{array}$ \\
\hline
\end{tabular}

Our initial search in databases using filters described in the research protocol resulted in the extraction of 1,073 articles. We controlled for other potential relevant publications that where not found directly from the database search by conducting a backward and forward reference search adding 117 articles potentially in scope. Next, we read the title and abstract of all identified items to remove duplications and studies that are outside the research scope. Further, we read the full text of the remaining articles (157 in total) to evaluate if they met the full criteria described in the research protocol, which resulted in 111 selected items. Of those, 26 articles using a case study methodology were used for our content analysis. Fig. 1 illustrates the selection process of the case study articles used for the systematic literature review and outlines the timeframe of their publication. The later shows that from 2016 there has been more effort from research to document agile case studies. 


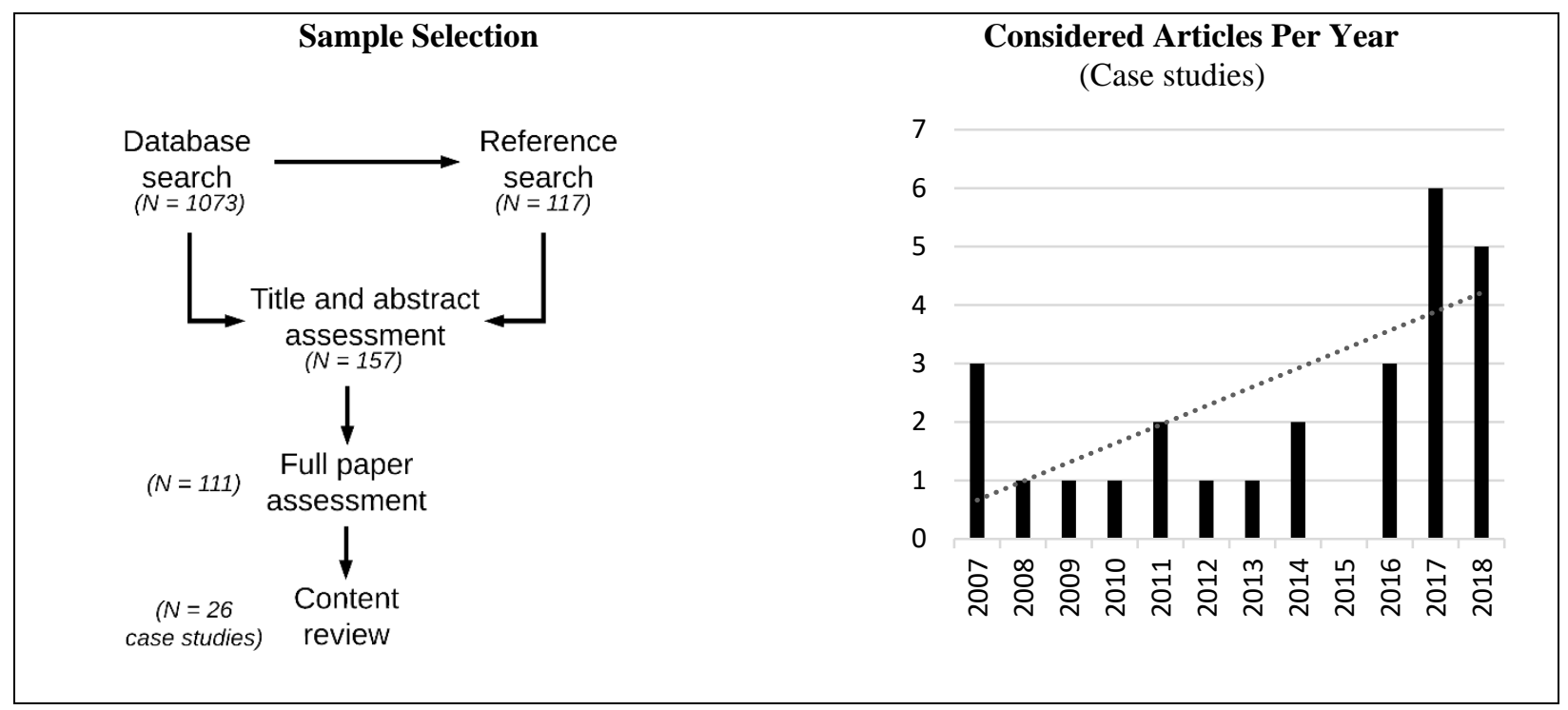

Fig. 1. Illustration of the systematic review process and timeframe of the selected case studies

\section{$4 \quad$ Analysis}

The analysis is based on guidance from Webster and Watson [8] and consists in synthetizing the selected literature based on a concept-centric morphological box that we developed following the procedure recommended by Mayring [20]. Correspondingly, we differentiate between three clusters linked with nine main categories as illustrated in Table 3 and describe in the following.

The first cluster, 'classification of case studies' aims to portray general aspects of the selected articles and includes the following deductive categories: publication type, literature domain, objective of the study, study design and study focus. With regard to the category 'publication type', we differentiate between 'journal' and 'conference' publication. As noted in the research protocol (see Table 2), other publication types have been excluded from the selection. The category 'literature domain' indicates the scientific field of each article. The category 'object of the study' points out the analytical frame of the case and the various positions that can be taken on the object of the study, differentiating between 'theory-testing', 'theory-seeking, and 'storytelling' [21]. The category 'study design' identifies the temporal structure of how change is studied [22]. Typically, research studies take either a 'snapshot perspective' examining " $a$ target event in a present moment in time," or a 'process perspective' examining "the evolution of an event over time" [23]. The last category of the first cluster points out that researchers studying an agile transformation process typically focus on one (or a combination) of strategic aspects of change (e.g. culture, leadership, dynamic capabilities), organizational aspects of change (e.g. models of organizing individuals and teams), and/or operational aspects of change (e.g. software development and requirements management) [24].

The second cluster, 'comprehension of agile transformation', focuses on understanding how agile is viewed and investigated from researchers and is composed of the following deductive categories: definition of agile and main topic of the study. The category 'definition of agile' aims to grasp how the concept of agile is specified (or not). Extant research typically considers agile either as a method (or an approach) (i.e. stipulating a method-notion) or acknowledge agile as a capability (i.e. stipulating a capability-notion). The category 'main topic of the study' is to highlight information about dominant agile themes that have been investigated in prior studies. The third cluster, 'application of agile transformation' depicts current application of agile transformation initiatives including two categories: industry type, and organizational size. 'Industry type' organizes case studies based on the sector groupings. 'Organizational size' distinguishes the case organizations considered in the examined study as either small and medium sized enterprises (SMEs) or large corporations. 
Table 3. Morphological Box for Analyzing Case Studies of Agile Transformations

\begin{tabular}{|c|c|c|c|c|c|c|c|c|}
\hline \multicolumn{5}{|c|}{ Classification of Case Studies } & \multicolumn{2}{|c|}{$\begin{array}{l}\text { Comprehension of } \\
\text { Agile Transformation }\end{array}$} & \multicolumn{2}{|c|}{$\begin{array}{c}\text { Application of Agile Transfor- } \\
\text { mation }\end{array}$} \\
\hline 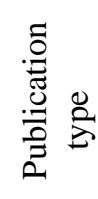 & 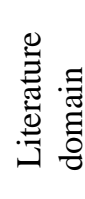 & 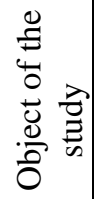 & 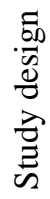 & 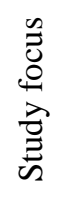 & 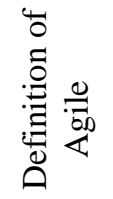 & 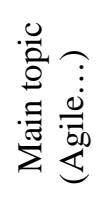 & 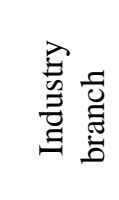 & 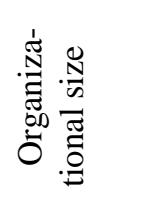 \\
\hline
\end{tabular}

\section{$5 \quad$ Result}

The concept matrix of agile transformation resulting from the analysis of the selected literature is presented in Table 4. The classification of case studies based on their 'publication type' reveals a somewhat proportional division between journal (54\%) and conference publication (46\%). Distinctively, the 'literature domain' category shows that agile studies are largely rooted in the Information System field (81\%) with a few contributions in the research areas of Strategic Management (8\%), Production Management (4\%), and Computer Science (4\%). Within the 'object of the study' category, authors mainly seek for theory-seeking (46\%) and storytelling (46\%). Much less, only $8 \%$ seek for theorytesting $[25,26]$. With regard to the 'study design', most authors follow a process perspective (77\%) to structure their investigation, while a snapshot perspective (23\%) has been used less [27-32]. Lastly, the 'study focus' category reveals that $19 \%$ of the articles consider (fully or partly) all three aspects of the agile transformation (i.e. strategic, organizational, and operational) [30, 33-36]. Further, $12 \%$ have a combined focus on organizational and operational aspects [37-39], while slightly more articles (19\%) have considered strategic and organizational aspects together [5, 16, 24, 40,41 . Lastly, $8 \%$ of the articles focus on strategic aspects only [29, 42], whilst $15 \%$ focus on organizational aspects only [31, 32, 43, 44].

The analysis highlighting the comprehension of agile transformation in terms of the category 'definition of agile' reveals an assertive tendency (42\%) to conceptualize (or refer to) agile as a method (or likewise, as an approach). Specific definitions related to this group of articles explain agile as an approach adopted to "regularly produce high quality software in a cost effective and timely manner via a value driven life-cycle" [39, p.4], and agile transformation as the "switch from a different development approach or work organization concept to agile methods" [5, p.3]. On the other hand, $15 \%$ of the articles conceptualize agile as a capability. Studies of this kind refer to agility broadly as the ability to move quickly and in a simple way [45], or somehow more detailed as the capacity to apply agile methods to digital transformations in order to create, react to, embrace, and learn from change while enhancing customer value [36]. Looking at the 'main topic' category, seven archetypes are evident. The dominant topic studied has been agile success factors (46\%) followed by agile challenges (31\%). In many cases, these two topics have been investigated together [24, 29, 33, 39, 41, 46, 47]. Further, the topics of agile metrics, agile scaling models, and agile change performance have been equally studied (19\%). The least investigated topics have been agile conceptualization and agile roles/teams (12\% each).

With regard to analyzing the application of agile transformation in terms of the category 'industry branch' six groupings were made. The prevailing setting were the case studies have been conducted is in the telecommunications (31\%) branch [25, 26, 29, 30, 42, 43, 47, 48]. The second group of cases are dispersed equally in the software industry and financial services (12\% each). Some attention has been given to studying agile transformation in education, and mass media ( $8 \%$ each), while only one case could be identified in retail [5]. In terms of the category 'organizational size', there is a clear dominance of articles assessing the transformation in large organizations (92\%), whilst the remaining $8 \%$ of them explore agile change in SMEs [28, 44]. 
Table 4: Result of the Concept Matrix of Agile Transformation Case Studies

\begin{tabular}{|c|c|c|c|c|c|c|c|c|c|c|c|c|c|c|c|c|c|c|c|c|c|c|c|c|c|c|c|c|}
\hline \multicolumn{3}{|c|}{ Articles } & & 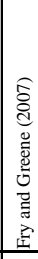 & 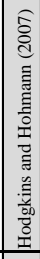 & 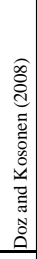 & 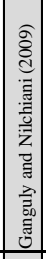 & 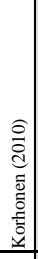 & 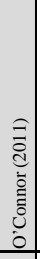 & 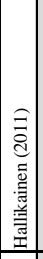 & 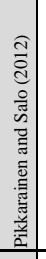 & 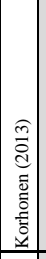 & 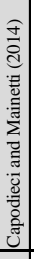 & 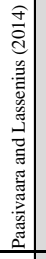 & 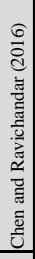 & 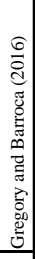 & 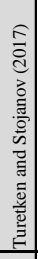 & 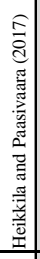 & 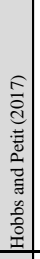 & 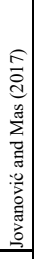 & 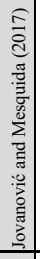 & 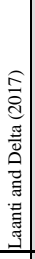 & 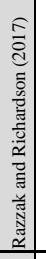 & 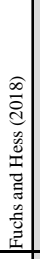 & 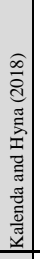 & 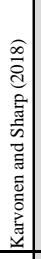 & 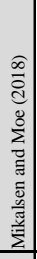 & 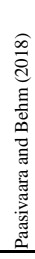 \\
\hline \multirow{14}{*}{ 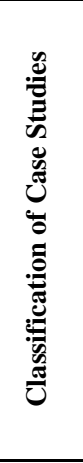 } & \multirow{2}{*}{ Publication type } & Journal & & & & $\mathrm{x}$ & $\mathrm{x}$ & & & & $\mathrm{x}$ & $\mathrm{x}$ & $\mathrm{x}$ & \begin{tabular}{l|l} 
\\
\end{tabular} & $\mathrm{x}$ & $\mathrm{x}$ & $\mathrm{x}$ & $\mathrm{x}$ & $\mathrm{x}$ & & $\mathrm{x}$ & & & & $\mathrm{x}$ & & & $\mathrm{x}$ \\
\hline & & Conference & $\mathrm{x}$ & $\mathrm{x}$ & $\mathrm{x}$ & & & $\mathrm{x}$ & $\mathrm{x}$ & $\mathrm{x}$ & & & & & & & & & & $\mathrm{x}$ & & $\mathbf{x}$ & $\mathrm{x}$ & $\mathrm{x}$ & & $\mathbf{x}$ & $\mathrm{x}$ & \\
\hline & \multirow{4}{*}{$\begin{array}{l}\text { Literature } \\
\text { domain }\end{array}$} & Information Systems & $\mathrm{x}$ & $\mathrm{x}$ & $\mathrm{x}$ & & & $\mathrm{x}$ & & $\mathrm{x}$ & $\mathrm{x}$ & $\mathrm{x}$ & & $\mathrm{x}$ & & $\mathrm{x}$ & $\mathrm{x}$ & $\mathrm{x}$ & $\mathrm{x}$ & $\mathrm{x}$ & $\mathrm{x}$ & $\mathrm{x}$ & $\mathrm{x}$ & $\mathrm{x}$ & $\mathrm{x}$ & $\mathrm{x}$ & $\mathrm{x}$ & $\mathrm{x}$ \\
\hline & & (Strategic) Management & & & & $\mathrm{x}$ & & & & & & & & & $\mathrm{x}$ & & & & & & & & & & & & & \\
\hline & & Production Management & & & & & $\mathrm{x}$ & & & & & & & & & & & & & & & & & & & & & \\
\hline & & Computer Science & & & & & & & & & & & $\mathrm{x}$ & & & & & & & & & & & & & & & \\
\hline & \multirow{3}{*}{$\begin{array}{l}\text { Object of the } \\
\text { study }\end{array}$} & Theory-testing & & & & & & $\mathrm{x}$ & & & & & $\mathrm{x}$ & & & & & & & & & & & & & & & \\
\hline & & Theory-seeking & & & & $\mathrm{x}$ & $\mathrm{x}$ & & & & & & & $\mathrm{x}$ & & $\mathrm{x}$ & $\mathrm{x}$ & & & $\mathrm{x}$ & $\mathrm{x}$ & $\mathrm{x}$ & & $\mathrm{x}$ & $\mathrm{x}$ & $\mathbf{x}$ & $\mathrm{x}$ & \\
\hline & & Storytelling & $\mathrm{x}$ & $\mathrm{x}$ & $\mathrm{x}$ & & & & $\mathrm{x}$ & $\mathrm{x}$ & $\mathrm{x}$ & $\mathrm{x}$ & & & $\mathrm{x}$ & & & $\mathrm{x}$ & $\mathrm{x}$ & & & & $\mathrm{x}$ & & & & & $\mathrm{x}$ \\
\hline & \multirow{2}{*}{ Study design } & Snapshot Perspective & & $\mathrm{x}$ & & & & & & & & & $\mathrm{x}$ & & $\mathrm{x}$ & & $\mathrm{x}$ & & $\mathrm{x}$ & & & $\mathrm{x}$ & & & & & & \\
\hline & & Process Perspective & $\mathrm{x}$ & & $\mathrm{x}$ & $\mathrm{x}$ & $\mathrm{x}$ & $\mathrm{x}$ & $\mathrm{x}$ & $\mathrm{x}$ & $\mathrm{x}$ & $\mathrm{x}$ & & $\mathrm{x}$ & & $\mathrm{x}$ & & $\mathrm{x}$ & & $\mathrm{x}$ & $\mathrm{x}$ & & $\mathbf{x}$ & $\mathrm{x}$ & $\mathrm{x}$ & $\mathrm{x}$ & $\mathrm{x}$ & $\mathrm{x}$ \\
\hline & \multirow{3}{*}{ Study focus } & Strategic & & & & $\mathrm{x}$ & & & & & $\mathrm{x}$ & & & & $\mathrm{x}$ & $\mathrm{x}$ & & (X) & & $\mathrm{x}$ & $\mathrm{x}$ & & & $\mathrm{x}$ & $\mathrm{x}$ & $\mathrm{x}$ & $\mathrm{x}$ & (X) \\
\hline & & Organizational & (X) & & (X) & & & & (X) & (X) & $\mathrm{x}$ & & & $\mathrm{x}$ & & $\mathrm{x}$ & $\mathrm{x}$ & $\mathrm{x}$ & $\mathrm{x}$ & $\mathrm{x}$ & $\mathrm{x}$ & $\mathrm{x}$ & $\mathrm{x}$ & $\mathrm{x}$ & $\mathrm{x}$ & $\mathrm{x}$ & $\mathbf{x}$ & $\mathrm{x}$ \\
\hline & & Operational & (X) & & (X) & & & & & & $\mathrm{x}$ & & & & & $\mathrm{x}$ & & $\mathrm{x}$ & $\mathrm{x}$ & & $\mathrm{x}$ & & & & & & (X) & \\
\hline \multirow{9}{*}{ 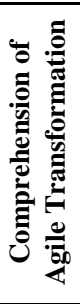 } & \multirow{2}{*}{$\begin{array}{c}\text { Definition of } \\
\text { Agile }\end{array}$} & Method-notion & (X) & $(\mathrm{X})$ & (X) & & & & (X) & (X) & (X) & & & (X) & & & (X) & (x) & $\mathrm{x}$ & & & & & $\mathrm{x}$ & & & & \\
\hline & & Capability-notion & & & & (X) & $\mathrm{x}$ & & & & & & & & & & & & & & & & & & & (X) & (X) & \\
\hline & \multirow{7}{*}{$\begin{array}{l}\text { Main topic } \\
\text { (Agile...) }\end{array}$} & Challenges & & & & & & & (X) & & $\mathrm{x}$ & & & & $\mathrm{x}$ & $\mathrm{x}$ & & & (X) & & & & & & $\mathrm{x}$ & $\mathrm{x}$ & & $\mathrm{x}$ \\
\hline & & Success factors & $\mathrm{x}$ & $\mathrm{x}$ & $\mathrm{x}$ & & & & $\mathbf{x}$ & $\mathrm{x}$ & $\mathrm{x}$ & & & & $\mathrm{x}$ & & & & $\mathrm{x}$ & & & & & & $\mathrm{x}$ & $\mathrm{x}$ & $\mathbf{x}$ & $\mathrm{x}$ \\
\hline & & Conceptualization & & & & $\mathrm{x}$ & & & & & & & & & & & & & & & & & & $\mathrm{x}$ & & $\mathrm{x}$ & & \\
\hline & & Metrics & & & & & $\mathrm{x}$ & (X) & & & & (X) & $\mathrm{x}$ & & & & & & & & & & (X) & & & & & \\
\hline & & Scaling Model & & & & & & & & & & & & & & & $\mathrm{x}$ & (X) & & $\mathrm{x}$ & & $\mathrm{x}$ & & & (X) & & & \\
\hline & & Change Performance & & & & & & $\mathrm{x}$ & & & & $\mathrm{x}$ & & & & & & $\mathrm{x}$ & (X) & & & & $\mathrm{x}$ & & & & & \\
\hline & & Roles/Teams & & & & & & & & & & & & & & & & & (X) & & $\mathrm{x}$ & & & & & & (X) & \\
\hline \multirow{8}{*}{ 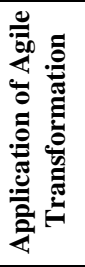 } & \multirow{6}{*}{ Industry branch } & Software & & $\mathrm{x}$ & & & $\mathrm{x}$ & & & & & & & & & & & & & & & & & & $\mathrm{x}$ & & & \\
\hline & & Telecommunications & & & & $\mathrm{x}$ & & $\mathrm{x}$ & & $\mathrm{x}$ & & $\mathrm{x}$ & & $\mathrm{x}$ & $\mathrm{x}$ & & & $\mathrm{x}$ & & & & & & & & & & $\mathrm{x}$ \\
\hline & & Financial services & & & & & & & & & & & & & & $\mathrm{x}$ & & & & & & & & $\mathrm{x}$ & & & $\mathrm{x}$ & \\
\hline & & Education & & & & & & & $\mathrm{x}$ & & & & & & & & & & & & & & & & & $\mathrm{x}$ & & \\
\hline & & Retail & & & & & & & & & & & & & & & & & & & & & & $\mathrm{x}$ & & & & \\
\hline & & Mass Media & $\mathrm{x}$ & & $\mathrm{x}$ & & & & & & & & & & & & & & & & & & & & & & & \\
\hline & \multirow{2}{*}{$\begin{array}{c}\text { Organizational } \\
\text { size }\end{array}$} & SMEs & & & & & & & & & & & $\mathbf{x}$ & & & & & & & & & & $\mathrm{x}$ & & & & & \\
\hline & & Large & $\mathrm{x}$ & $\mathrm{x}$ & $\mathrm{x}$ & $\mathrm{x}$ & $\mathbf{x}$ & $\mathrm{x}$ & $\mathbf{x}$ & $\mathrm{x}$ & & $\mathbf{x}$ & & $\mathrm{x}$ & $\mathrm{x}$ & $\mathrm{x}$ & $\mathrm{x}$ & $\mathbf{x}$ & $\mathbf{x}$ & $\mathbf{x}$ & $\mathrm{x}$ & $\mathbf{x}$ & & $\mathbf{x}$ & $\mathbf{x}$ & $\mathbf{X}$ & & $\mathbf{X}$ \\
\hline
\end{tabular}

\section{Discussion}

We discuss our findings in light of recent agile practitioners' concerns as pointed out by Gregory and Barroca [34]. Our aim was to identify topics that deserve more attention from research. Accordingly, we spot three priority areas 'Governance of Agile Scaling', 'Dealing with Legacy Systems', and 'Capabilities for the Agile Way', and elaborate them before pointing out some methodological limitations.

Firstly, extant work has not yet established compelling governance and oversight mechanisms needed to handle agile scaling. This issue is nowadays evermore imperative as agile transformation seems to follow atypical change patterns [5] and requires a shift from the traditional leadership styles [10, 34]. The literature addressing strategic aspects of the transformation, which map to our category 'study focus' highlight the importance of defining the necessary goals of the transformation, which require oversight and a customized process model [33, 35] as well as developing new roles and requirements for renewed management practices [29, 30, 40]. The governance role is imperative in envisioning, formulating and communicating change facets but recent evidence shows a lot of hurdles in this respect [24]. Hence, researchers should devote particular attention to develop opportune governance mechanisms that can benefit leaders to guide and control agile transformation initiatives.

Secondly, a critical challenging area with sparse information relates to dealing with legacy systems during the agile transition. Failure to establish a clear approach to handle legacy systems often results in organizations trying to work in an agile way in a non-agile environment (i.e. with traditional organizational structures) [34]. Surprisingly, when 
analyzing the 'Agile main topics' investigated in previous studies, the legacy system issues seem to be largely overlooked. We call for future work to explore adequate strategies that enable a smooth transition and continuous integration of legacy systems into the agile world.

Thirdly, there is little investigation on the capabilities needed to succeed in the agile way of working. Extant research propounds the view that renewed skills and a quick learning environment are compulsory to absorb agile practices and new organizational forms [34]. Inevitably, new organizational capabilities at various levels (e.g. ordinary or dynamic) are required at different stages of the agile change. Yet, our findings indicate very little practice-grounded research studies that increase our understanding about this set of new capabilities that benefit agile scaling and subsequently add value to the organization. What is more, apart from a few exceptions $[24,49]$ identified in the intersection between the 'capability-notion' and the related 'conceptualization' studies in the concept matrix, there seems to be also a lack of theoretical contributions grasping the capability construct in the agile transformation context. Therefore, more research is needed utilizing various lenses (i.e. practical or/and theoretical) to grasp distinct, emergent capabilities vital for the agile journey and to suggest appropriate ways to develop them.

Although our search process included 9 scientific databases, the analysis is limited to 26 selected articles that were found using a case-study methodology. We did not conduct an exhaustive author search, which could have potentially resulted in more selected publications. In attempt to examine highly qualified research findings, we restricted our selection to peer-reviewed papers only. However, nearly half of the selected articles were published in conference proceedings (considered less mature than journal publications). For future investigations within this research stream, more IS journal papers using different methodologies can be considered.

\section{References}

1. Beck, K., et al. Manifesto for agile software development. 2001 [cited October 31, 2019; Available from: http://www.agilemanifesto.

2. Dikert, K., M. Paasivaara, and C. Lassenius, Challenges and success factors for large-scale agile transformations: A systematic literature review. The Journal of Systems and Software, 2016. 119: p. 87-108.

3. $\quad$ Bharadwaj, A., et al., Digital Business Strategy: Toward a Next Generation of Insights. MIS Quarterly, 2013. 37(2): p. 471-482.

4. $\quad$ Denning, S., How to make the whole organization "Agile". Strategy \& Leadership, 2016. 44(4): p. 10-17.

5. Fuchs, C. and T. Hess, Becoming Agile in the Digital Transformation: The Process of a LargeScale Agile Transformation, in Thirty Ninth International Conference on Information Systems. 2018: San Francisco.

6. Simons, H., Case study research in practice. 2009, London: SAGE.

7. Yin, R.K., Case Study Research. 2003, Thousand Oaks: Sage.

8. Webster, J. and R.T. Watson, Analyzing the Past to Prepare for the Future: Writing a Literature Review. MIS Quarterly, 2002. 26(2): p. xiii-xxiii.

9. Tolf, S., et al., Agile, a guiding principle for health care improvement? International Journal of Health Care Quality Assurance, 2015. 28(5): p. 468-493.

10. Gregory, P., et al. Agile challenges in practice: a thematic analysis. in 16th International Conference on Agile Software Development. 2015. Helsinki: XP 2015.

11. Appelbaum, S.H., et al., The challenges of organizational agility (part 1). Industrial and Commercial Training, 2017. 49(1): p. 6-14.

12. Appelbaum, S.H., et al., The challenges of organizational agility: part 2. Industrial and Commercial Training, 2017. 49(2): p. 69-74.

13. Paterek, P. Agile Transformation in Project Organization: Knowledge Management Aspects and Challenges. in 18th European Conference on Knowledge Management ECKM2017. 2017. International University of Catalonia, Spain.

14. Abdalhamid, S. and A. Mishra, Adopting of Agile methods in Software Development Organizations: Systematic Mapping. TEM Journal, 2017. 6(4): p. 817-825.

15. Sońta-Drączkowska, E., From Agile Project Management to Agile Organization? - a Literature Review. Przedsiębiorczość i Zarządzanie, 2018. 6(1): p. 231-242.

16. Putta, A., M. Paasivaara, and C. Lassenius, Benefits and Challenges of Adopting the Scaled Agile Framework (SAFe): Preliminary Results from a Multivocal Literature Review, in Product-Focused Software Process Improvement. PROFES 2018. , K.M.e. al., Editor. 2018, Springer, Cham: Lecture Notes in Computer Science. p. 334-351.

17. Putta, A. Scaling agile software development to large and globally distributed large-scale organizations. in ICGSE '18 Proceedings of the 13th International Conference on Global Software Engineering 2018. Gothenburg, Sweden.

18. Tranfield, D., D. Denyer, and P. Smart, Towards a methodology for developing evidence-informed management knowledge by means of systematic review. British Journal of Management, 2003. 14(3): p. 207-222.

19. Okoli, C. and K. Schabram, A guide to conducting a systematic literature review of information systems research. Sprouts: Working Papers on Information System, 2010. 10(26): p. 1-49.

20. Mayring, P., Qualitative content analysis: theoretical foundation,basic procedures and software solution. Klagenfurt, AT, 2014. p. 143 
21. Thomas, G., A Typology for the Case Study in Social Science Following a Review of Definition, Discourse, and Structure. Qualitative Inquiry, 2011. 17(6): p. 511-521.

22. Goldstein, H., Longitudinal Studies and The Measurement of Change. Journal of the Royal Statistical Society. , 1968. 18(2): p. 93-117.

23. $\quad$ Sandelowski, M., Time and Qualitative Research. Research in Nursing \& Health, 1999. 22: p. 79-87.

24. Karvonen, T., H. Sharp, and L. Barroca. Enterprise Agility: Why Is Transformation so Hard? in Agile Processes in Software Engineering and Extreme Programming. XP 2018. 2018. Lecture Notes in Business Information Processing: Springer, Cham.

25. Korhonen, K., Exploring Defect Data, Quality and Engagement during Agile Transformation at a Large Multisite Organization, in Agile Processes in Software Engineering and Extreme Programming. XP 2010., A. Sillitti, et al., Editors. 2010, Springer, Berlin, Heidelberg: Lecture Notes in Business Information Processing. p. 88-102.

26. Korhonen, K., Evaluating the impact of an agile transformation: a longitudinal case study in a distributed context. Software Quality Journal, 2013. 21(4): p. 599-624.

27. Fry, C. and S. Greene. Large Scale Agile Transformation in an On-Demand World. in IEEE. 2007. Washington, USA

28. Capodieci, A., L. Mainetti, and L. Manco, A Case Study to Enable and Monitor Real IT Companies Migrating from Waterfall to Agile, in Computational Science and Its Applications, Murgante B. et al., Editor. 2014, Lecture Notes in Computer Science, Springer, Cham: ICCSA 2014.

29. Chen, R.R., R. Ravichandar, and D. Proctor, Managing the transition to the new agile business and product development model: Lessons from Cisco Systems. Business Horizons, 2016. 59(6): p. 635-644.

30. Heikkila, V.T., et al., Managing the requirements flow from strategy to release in large-scale agile development: a case study at Ericsson. Empir Software Eng, 2017. 22(6): p. 2892-2936.

31. Laanti, M. and N. Delta. Agile Transformation Model for Large Software Development Organizations. in XP '17 Proceedings of the XP2017 Scientific Workshops 2017. Cologne, Germany: ACM New York.

32. Turetken, O., I. Stojanov, and J.J.M. Trienekens, Assessing the adoption level of scaled agile development: a maturity model for Scaled Agile Framework. Special Issue: Recent Advances in Agile Software Product Development, 2017. 29(6): p. 1-18.

33. Pikkarainen, M., et al., Strengths and barriers behind the successful agile deployment-insights from the three software intensive companies in Finland. Empirical Software Engineering, 2012. 17(6): p. 675-702.

34. Gregory, P., et al., The challenges that challenge: Engaging with agile practitioners' concerns. Information and Software Technology, 2016. 77: p. 92-104.

35. Jovanović, M., et al., Towards the Development of a Sequential Framework for Agile Adoption, in Software Process Improvement and Capability Determination. SPICE 2017., A. Mas, et al., Editors. 2017, Springer, Cham: Communications in Computer and Information Science. p. 30-42.

36. Mikalsen, M., et al. Agile Digital Transformation: A Case Study of Interdependencies. in Thirty Ninth International Conference on Information Systems. 2018. San Francisco.

37. Cloke, G. GET YOUR AGILE FREAK ON! Agile Adoption at Yahoo! Music. in Agile 2007. 2007. Washington, DC, USA: Computer Society.

38. Hodgkins, P. and L. Hohmann. Agile Program Management: Lessons Learned from the VeriSign Managed Security Services Team. in Agile 2007. 2007. Washington, DC, USA IEEE

39. Hobbs, B. and Y. Petit, Agile Methods on Large Projects in Large Organizations. Project Management Journal, 2017. 48(3): p. 3-19

40. Jovanović, M., et al., Transition of organizational roles in Agile transformation process: A grounded theory approach. Journal of Systems and Software, 2017. 133: p. 174-194.

41. Kalenda, M., P. Hyna, and B. Rossi, Scaling agile in large organizations: Practices, challenges, and success factors. Software Evolution and Process, 2018. 30(10): p. 1-24.

42. Doz, Y. and M. Kosonen, The Dynamics of Strategic Agility: NOKIA'S ROLLERCOASTER EXPERIENCE. California Management Review, 2008. 50(3): p. 95-118.

43. Paasivaara, M. and C. Lassenius, Communities of practice in a large distributed agile software development organization - Case Ericsson. Information and software technology, 2014. 56(12): p. 1556-1577.

44. Razzak, M.A., I. Richardson, and S. Beecham, Transition from Plan Driven to SAFe: Periodic Team Self-Assessment, in Product-Focused Software Process Improvement. PROFES 2017, M. Felderer, et al., Editors. 2017, Springer, Cham: Lecture Notes in Computer Science.

45. Ganguly, A., R. Nilchiani, and J.F. School, Evaluating agility in corporate enterprises. Int. J.ProductionEconomics, 2009. 118(2): p. 410-423.

46. O’Connor, C.P. Anatomy and Physiology of an Agile Transition. in Agile Conference. 2011. Salt Lake City, USA IEEE. 47. $\quad$ Paasivaara, M., et al., Large-scale agile transformation at Ericsson: a case study. Empir Software Eng, 2018. 23(5): p. 2550-2596.

48. Hallikainen, M. Experiences on Agile seating, facilities and solutions. in IEEE Sixth International Conference on Global Software Engineering. 2011.

49. Doz, Y.L. and M. Kosonen, Embedding Strategic Agility: A Leadership Agenda for Accelerating Business Model Renewal. Long Range Planning, 2010. 43(2-3): p. 370-382. 